\title{
Features of Ground Flashes before and after the Massive Earthquake Observed from Kathmandu, Nepal
}

\section{Pitri Bhakta Adhikari}

Journal of Nepal Physical Society

Volume 4, Issue 1, February 2017

ISSN : 2392-473X

Editors:

Dr. Gopi Chandra Kaphle

Dr. Devendra Adhikari

Mr. Deependra Parajuli

JNPS, 4 (1), 11-22 (2017)

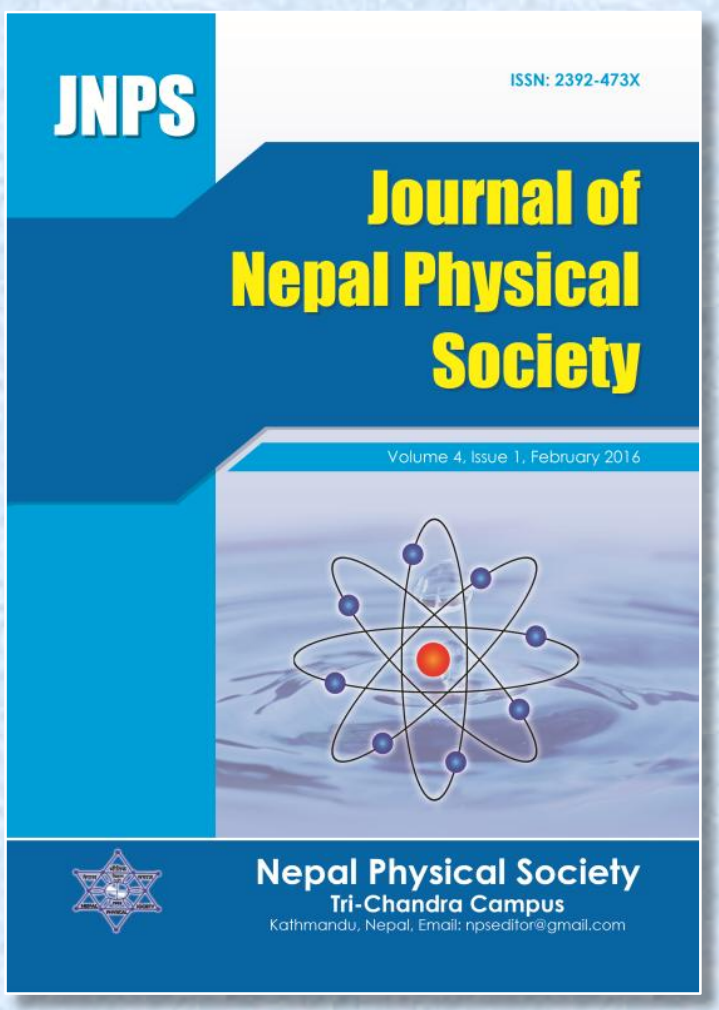

Published by:

Nepal Physical Society

P.O. Box : 2934

Tri-Chandra Campus

Kathmandu, Nepal

Email: npseditor@gmail.com 


\title{
Features of Ground Flashes before and after the Massive Earthquake Observed from Kathmandu, Nepal
}

\author{
Pitri Bhakta Adhikari \\ Central Department of Physics, Tribhuvan University, Kirtipur, Nepal \\ Corresponding Email: pitribhakta_adhikari@hotmail.com
}

\begin{abstract}
Lightning electric field signatures pertinent to the subtropical thunderstorms occuring over the rugged terrain have been measured and recorded at a hilly station Kathmandu, Nepal. In the present work signatures of the ground flashes have been selected from all the records before and after the massive earthquake and were analyzed. It is the first time that such signatures were analyzed and presented. Two hundred and eight flashes (208) of the totals of six hundred and forty-five (645) flashes were selected from about eight thunderstorm days before and after the massive earthquake and analyzed. Majority of the positive ground flashes were found to be single stroke ones whereas the average number of strokes per flash is found to be 1.13 with a maximum value of 4 , after the massive earthquake.
\end{abstract}

Keywords: Positive and negative lightning, Massive earthquake, Electric field signatures of Lightning.

\section{INTRODUCTION}

Lightning positive ground flashes, that in general transport the positive charge from the cloud to the ground, occur very rarely. Of all the cloud to ground flashes, the positive ground flashes account for about 10\% (Rakov and Uman, 2003). Considering the tripole structure of a thundercloud, the paucity of the positive ground flashes can easily be justified. However, the charge structure of the cloud still remains a mystery. Because of the paucity of their occurrence, positive ground flashes are considerably less studied and hence less understood as compared to their negative counterparts (Nag and Rakov, 2012).

According to Williams (1989), the lightning activity itself follows a specific pattern with the intracloud (IC) lightning normally appearing in the developing stage followed by the cloud-to-ground (CG) lightning during the mature stage, whereas, both types of lightning can occur in the decaying stage of thunderstorms. Lightning in thunderstorms is strongly linked to the microphysics and dynamics of thunderstorms and, hence, changes in the lightning activity can tell us about changes in the internal processes within the thunderstorms (Price, 2008; Qie et al., 2013). Positive ground flashes are of much interest to the lightning community because of their possible association with the upper atmospheric discharges, such as sprites, and due to the magnitude of current possessed by them. The positive ground flashes may also be related to the severe weather phenomena such as tornadoes, hails, derecho etc.

The atmospheric structure and hydrometeorological processes along the south slopes of the Himalayas are not well known or well documented mainly because of the rugged and remote terrain (Barros and Lang, 2003). The hydrometeoroloical processes over the rugged terrain, development of the thundercloud, its charge structure and the signatures of lightning flashes are of much interest to the scientific community. Monitoring the lightning activity over Kathmandu and its vicinity for 21 months, Baral and Mackerras (1993), found the average proportion of positive ground flashes to the total ground flashes to be 0.28 .

Signatures of the lightning electromagnetic field pertinent to the subtropical mountainous country Nepal are of much interest to the scientific community as the rugged terrain and high hills may influence the occurrence and the nature of the lightning strikes on the period of before and after the massive earthquake.

\section{EXPERIMENTAL SETUP (INSTRUMENTATION AND MEASUREMENT)}

The lightning electric fields were recorded at a measuring station in Kathmandu, Nepal, which is situated at $27^{\circ} 44^{\prime} \mathrm{N}$; and $85^{\circ} 19^{\prime} \mathrm{E}$; and about 1300 $\mathrm{m}$ height above the sea level. Two hundred thirty- 
six positive and sixteen negative strokes have been recorded from the measuring station and analysed. The vertical electric fields of the flashes were sensed by the flat plate antenna fixed on a $1.5 \mathrm{~m}$ high post and was placed on the rooftop of a house at a physical height of about $12 \mathrm{~m}$ from ground. The parallel plate of capacitance $60 \mathrm{pF}$ was connected to a buffer circuit through a $60 \mathrm{~cm}$ long RG 58 coaxial cable. The signal passing through buffer amplifier was fed to the digital storage oscilloscope (Pico-scope 6404D) through a $20 \mathrm{~m}$ long RG 58coaxial cable. The signals so received were recorded by the pico-scope whose window size was varied from $200-500 \mathrm{~ms}$ at different sampling rate of $40-312 \mathrm{MS} /$ seconds. A schematic diagram of the antenna and recording system that has been used in this study is adopted from Sharma et al. (2008).

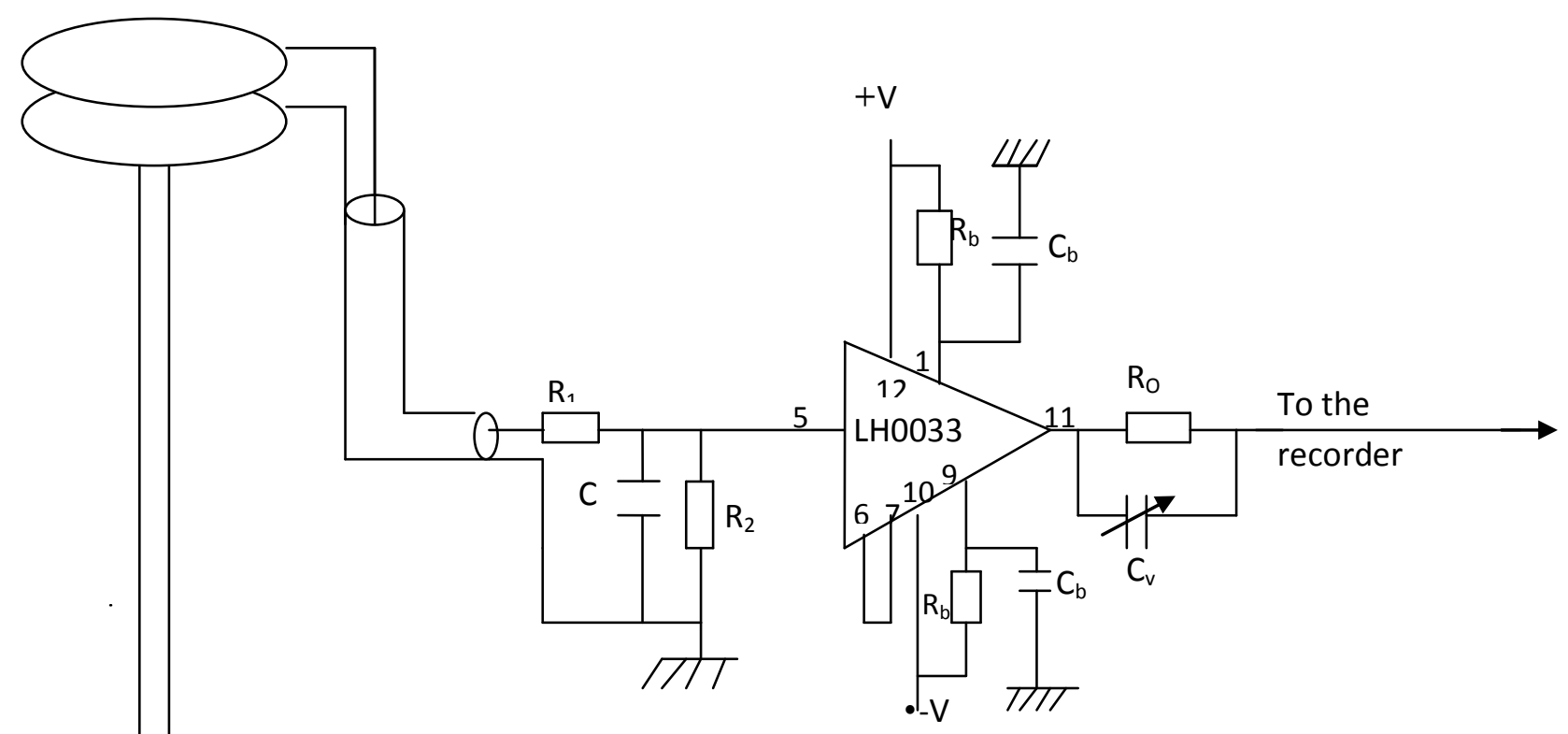

Fig. 1. The parallel plate antenna and the buffer circuit used for the electric field.

\section{OBSERVATION}

Electric fields generated by the lightning flashes were recorded during the pre - monsoon 2015. A total of two hundred and eight positive and sixteen negative ground flashes were recorded and analyzed. Most of the positive ground flashes were found to have single strokes, however, some of the positive ground flashes consisted of two or more than two return strokes but in negative ground flashes have only single strokes. The data acquired on the different days of March, April and May 2015, and analysed in the study are depicted in the table 1 . As is depicted in table 1, a total of six hundred and forty-five lightning flashes were recorded on different eight days of pre-monsoon, out of which two hundred and eight strokes were observed to be positive where as sixteen only observed to be negative ground flashes.
We have studied the various conceptual cloud charges leading to production of positive lightning with a view towards an explanation of its observed properties. Data for fifty-seven (57) cloud to ground flashes in which sixty-four (64) positive strokes were observed within the month of March and April before the earthquake. One hundred fiftyone cloud to ground flashes in which one hundred seventy two positive strokes were recorded after the earthquake of large magnitude of 7.6 rector scale on $25^{\text {th }}$ April, magnitude of 6.8 rector scale on $26^{\text {th }}$ April, magnitude of 6.9 rector scale on $12^{\text {th }}$ may. Within the period of twenty-four (24) days,(April 25 to may 18 ) two hundred forty two (242) times recorded the earthquake of magnitude above four rector scale. The data of one hundred seventy-two positive strokes within the period of earthquake were recorded on the date 2015-05-11 and 16 as shown in Table 1. 
We measured the electric field, rise time, zerocrossing time and field width at half maximum (FWHM) of the data presented here in Kathmandu, Nepal. The electric field sensor consisted of a circular flat-plate antenna followed by a buffer circuit. We have recorded cloud to ground flashes on the different day of March, April and May 2015 as shown in Table 1 below.

Table 1: Cloud to ground flashes on the different day of March, April and May 2015.

\begin{tabular}{|l|l|l|l|l|l|}
\hline $\begin{array}{c}\text { Before Earth } \\
\text { quake }\end{array}$ & \multicolumn{2}{|c|}{$\begin{array}{c}\text { Total } \\
\text { recorded } \\
\text { flash }\end{array}$} & \multicolumn{2}{|c|}{\begin{tabular}{c}
\multicolumn{2}{c|}{ Total Flash containing Return } \\
Stroke
\end{tabular}} & \multicolumn{2}{c|}{$\begin{array}{c}\text { Cloud and other } \\
\text { flashes }\end{array}$} & $\begin{array}{c}\text { Total positive } \\
\text { R.S }\end{array}$ \\
\hline $2015-03-30$ & 50 & 26 & 5 & 19 & 29 \\
\hline $2015-03-31$ & 1 & 1 & 0 & 0 & 1 \\
\hline $2015-04-12$ & 20 & 13 & 0 & 7 & 14 \\
\hline $2015-04-15$ & 48 & 1 & 8 & 39 & 1 \\
\hline $2015-04-16$ & 104 & 6 & 3 & 95 & 8 \\
\hline $2015-04-17$ & 70 & 10 & 0 & 60 & 11 \\
\hline Total & 293 & 57 & 16 & 220 & 64 \\
\hline
\end{tabular}

After Earth quake

\begin{tabular}{|l|l|l|l|l|l|}
\hline $2015-05-11$ & 132 & 76 & 0 & 56 & 82 \\
\hline $2015-05-16$ & 220 & 75 & 0 & 145 & 90 \\
\hline Total & 352 & 151 & 0 & 201 & 172 \\
\hline Grand total & 645 & 208 & 16 & 421 & 236 \\
\hline
\end{tabular}

Out of two hundred and eight positive ground flashes, one hundred and eighty five flashes were found to have single strokes where as nineteen flashes have two strokes, three flashes have three strokes, and single flash have four strokes. Table 2 depicts the occurrence of the positive ground flashes on different days along with their multiplicity.

Table 2: Occurrence of positive ground flashes on different thunderstorm days along with their multiplicity.

\begin{tabular}{|l|l|l|l|l|l|l|l|l|l|}
\hline Date of flash & $3-30$ & $3-31$ & $4-12$ & $4-15$ & $4-16$ & $4-17$ & $5-11$ & $5-16$ & Total \\
\hline No of flash & 26 & 1 & 13 & 1 & 6 & 10 & 76 & 75 & 208 \\
\hline Flash containing & 23 & 1 & 12 & 1 & 4 & 9 & 72 & 63 & 185 \\
\hline 1 RS & 3 & 0 & 1 & 0 & 2 & 1 & 3 & 9 & 19 \\
\hline 2 RS & 0 & 0 & 0 & 0 & 0 & 0 & 0 & 3 & 3 \\
\hline 3 RS & 0 & 0 & 0 & 0 & 0 & 0 & 1 & 0 & 1 \\
\hline 4 RS & 29 & 1 & 14 & 1 & 8 & 11 & 82 & 90 & 236 \\
\hline Total no of strokes &
\end{tabular}

\section{BEFORE EARTHQUAKE}

We have recorded two hundred ninety three total flashes within the month of the March and April 2015, before earthquake. Among them the fifty seven cloud flash were taken in which sixty-four positive return strokes and sixteen negative return strokes were recorded. We have measured the rise time $\left(t_{r}\right)$, Zero crossing time $\left(t_{z}\right)$, field width at the half -maximum (FWHM) and amplitude of the waves which are the basic parameter of the waves. Before the Earth-quake, fifty seven positive ground flashes were recorded in which sixty four positive 
strokes and sixteen flashes containing sixteen negative strokes were analyzed. These are expressed also in the Table 1.

On these fifty Seven Ground flashes containing sixty four positive strokes, the analysis has been done. For the analysis the arithmetic mean, Geometric mean, Median, Maximum value, Minimum value, Range, correlation coefficient, Standard Deviation, Variance of the parameter etc. of the parameter rise time, Zero crossing time, FWHM, amplitudes of the waves were found. The average of the rise time is $10.15 \mu \mathrm{s}$, in which G. M. is $7.96 \mu \mathrm{s}$. The average of zero-crossing time is $32.30 \mu \mathrm{s}$ and G. M. is only $24.31 \mu \mathrm{s}$. The average of FWHM is $15.38 \mu$ s but G. M. is only $11.82 \mu \mathrm{s}$.
Similarly, the mean amplitude of the wave is $567.32 \mathrm{mV}$ but the G.M. is only $448.75 \mathrm{mV}$.

On these data, the rise time varies from $1.08 \mu$ s to $44.97 \mu$ s. So the range is $43.89 \mu$ s. Similarly, the zero-crossing time varies from $2.35 \mu$ s to $252.8 \mu \mathrm{s}$ whose range is $250.45 \mu \mathrm{s}$. The FWHM varies from $1.3 \mu \mathrm{s}$ to $63.70 \mu \mathrm{s}$, so the range is $62.40 \mu \mathrm{s}$. The amplitude of the waves varies from $103.1 \mathrm{mV}$ to $2949 \mathrm{mV}$ having range $2845.9 \mathrm{mV}$. The standard deviation of the rise time is $8.28 \mu \mathrm{s}$ and the standard deviation of zero-crossing time, FWHM and amplitude are $34.13 \mu \mathrm{s}, 12.35 \mu \mathrm{s}$ and 491.76 $\mathrm{mV}$ respectively. These data are summarized in the following table 3 .

Table 3: Statistics of different parameters for positive return strokes before the earthquake.

\begin{tabular}{|l|l|l|l|l|}
\hline & \multicolumn{1}{|c|}{ Rise time $\left(\mathbf{t}_{\mathbf{r}}\right)$} & \multicolumn{1}{|c|}{ Zero-crossing time $\left(\mathbf{t}_{\mathbf{z}}\right)$} & \multicolumn{1}{c|}{ FWHM } & Amplitude \\
\hline Average & 10.15 & 32.30 & 15.38 & 567.32 \\
\hline G. M. & 7.96 & 24.31 & 11.82 & 448.75 \\
\hline Max & 44.97 & 252.8 & 63.70 & 2949 \\
\hline Min & 1.08 & 2.35 & 1.30 & 103.1 \\
\hline Range & 43.89 & 250.45 & 62.40 & 2845.9 \\
\hline Median & 7.48 & 24.85 & 12.45 & 406.7 \\
\hline S. D. & 8.28 & 34.13 & 12.35 & 491.76 \\
\hline $\begin{array}{l}\text { Correlation } \\
\text { Coefficient }\end{array}$ & $\mathrm{R}_{12} \mathrm{R}_{13} \mathrm{R}_{14}$ & 0.25 & 0.52 & 0.15 \\
\hline & & & 0.52 & 0.04 \\
\hline & $\mathrm{R}_{23} \mathrm{R}_{24}$ & & & 0.03 \\
\hline
\end{tabular}

The correlation coefficient between the rise time and zero-crossing time is 0.25 . The correlation coefficient between rise time and FWHM is 0.52 and correlation coefficient of rise time and amplitude is 0.15 . The correlation coefficient between zero-crossing time and FWHM is 0.52 which is the same as the correlation coefficient between rise time and FWHM. The correlation coefficient of amplitude with zero-crossing time and FWHM are 0.04 and 0.03 respectively. This relation of amplitude is very weak with zerocrossing time and FWHM.

From the above data, the relation of amplitude with zero-crossing time and FWHM is very poor. The relation of FWHM with zero-crossing time and rise time is same. These relations of the parameters are also shown in figure 2 below.

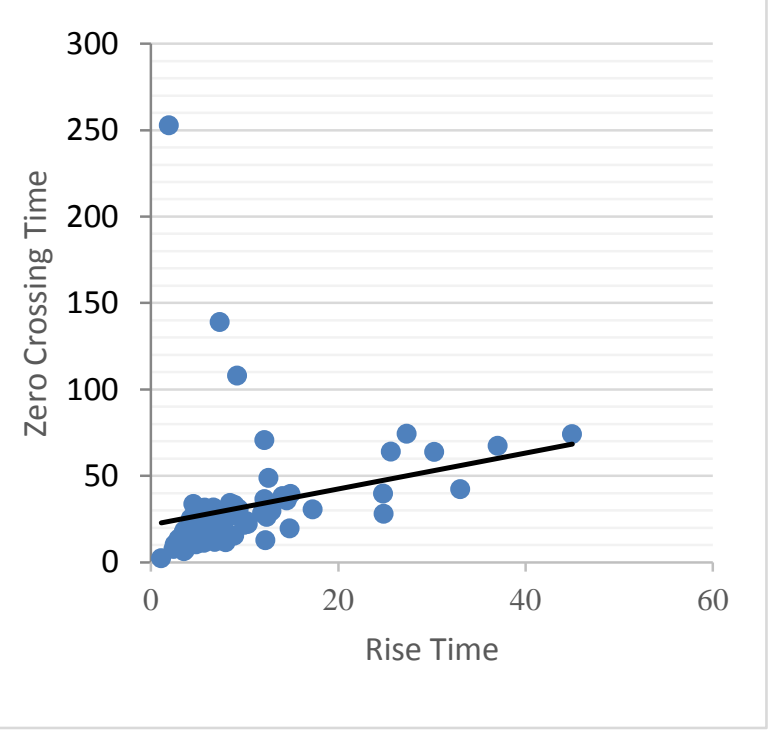

(a) 


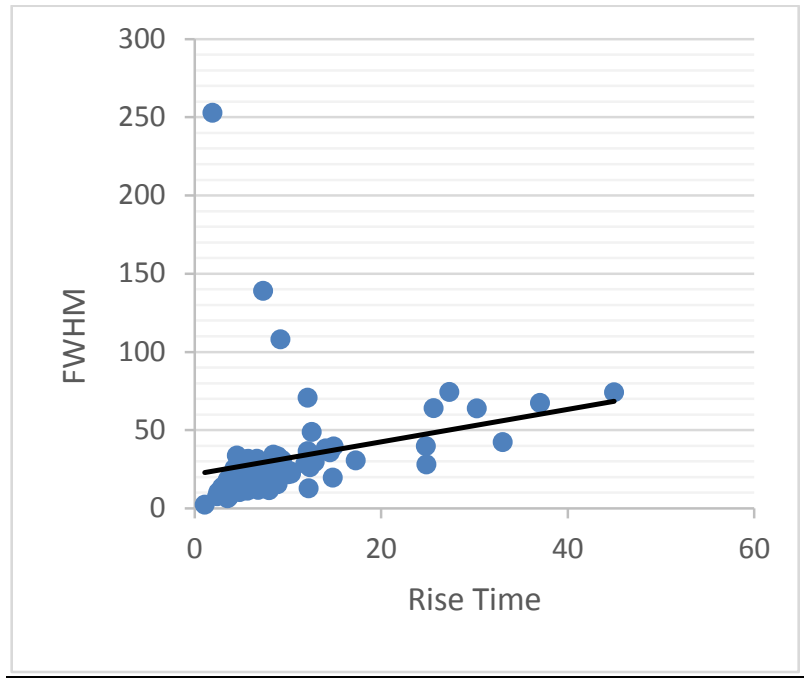

(b)

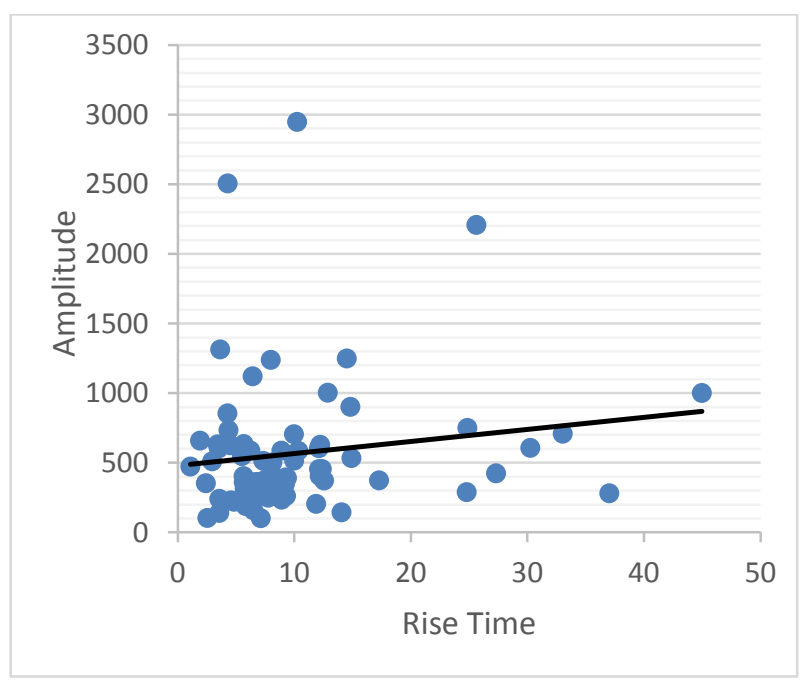

(c)

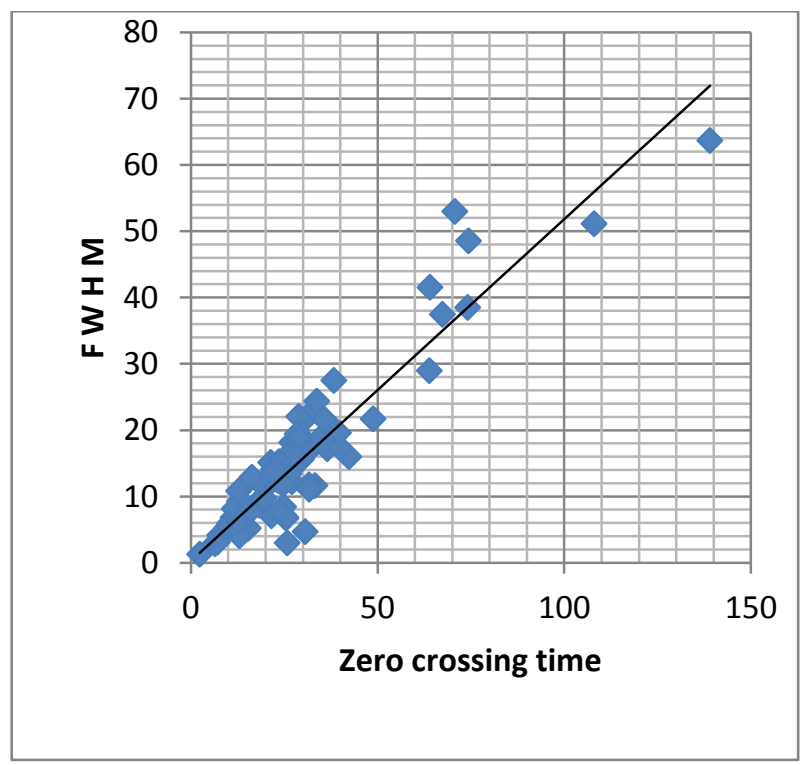

(d)

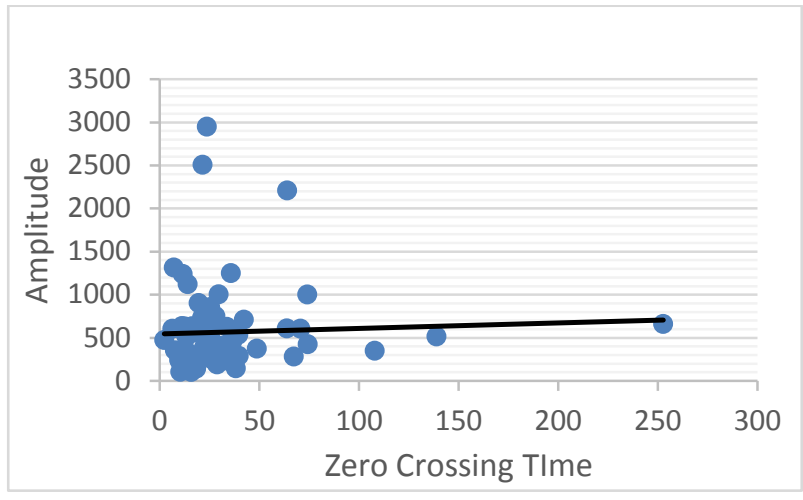

(e)

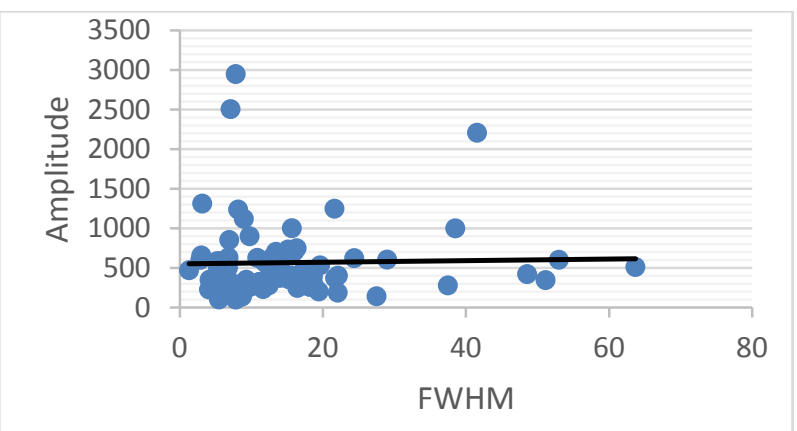

(f)

Fig. 2. Graph of the parameters of positive flashes before the earthquake (a) Rise time vs zero-crossing time (b) Rise time vs FWHM (c) Rise time vs Amplitude (d) Zero-crossing time vs FWHM (e) Zero-crossing time vs Amplitude (f) FWHM vs Amplitude.

(Note: The value of correlation coefficient(r) is interpreted as, if $r$ is less than 0.2, the correlation is very weak. If $r$ is greater than and equal to 0.2 and less than 0.4 , the correlation coefficient is weak. If $r$ is greater than and equal to 0.4 and less than 0.6, the correlation coefficient is moderate. If $r$ is greater than and equal to 0.6 and less than 0.8, the correlation coefficient is good. If $r$ is greater than 0.8 , the correlation is very good. However, the value of $r^{2}$ is preferred for more precise analysis and is called coefficient of determination.)

Similarly, for the negative strokes of 16 , the same rise time, zero-crossing time, FWHM and amplitudes were taken and average, G.M., median, standard deviation etc. of them are calculated.

The average of the rise time is $2.39 \mu \mathrm{s}$, in which G.M. is $1.82 \mu \mathrm{s}$. The average of zero-crossing time is $8.51 \mu \mathrm{s}$ and G.M. is only $5.68 \mu \mathrm{s}$. The average of FWHM is $4.94 \mu \mathrm{s}$ but G.M. is only $2.54 \mu \mathrm{s}$. Similarly, the mean amplitude of the wave is $\mathbf{1 7 9 . 2}$ $\mathrm{mV}$ but the G.M. is only $136.04 \mathrm{mV}$. 
The standard deviation of the rise time is $1.54 \mu \mathrm{s}$ and the standard deviation of zero-crossing time, FWHM and amplitude are $6.19 \mu \mathrm{s}, 4.26 \mu \mathrm{s}$ and
$137.56 \mathrm{mV}$ respectively. These data were depicted in the following table 4.

Table 4: Statistics of different parameters for negative return strokes.

\begin{tabular}{|l|l|l|l|l|}
\hline & \multicolumn{1}{|c|}{ Rise time $\left(\mathbf{t}_{\mathbf{r}}\right)$} & \multicolumn{1}{|c|}{$\begin{array}{c}\text { Zero-crossing } \\
\text { time }\left(\mathbf{t}_{\mathbf{z}}\right)\end{array}$} & \multicolumn{1}{|c|}{ FWHM } & Amplitude \\
\hline No. of strokes & 16 & 16 & 16 & 16 \\
\hline Average & 2.39 & 8.51 & 4.94 & 179.2 \\
\hline G.M. & 1.82 & 5.68 & 2.54 & 136.04 \\
\hline Median & 1.87 & 7.89 & 4.42 & 127.85 \\
\hline Standard Deviation & 1.54 & 6.19 & 4.26 & 137.56 \\
\hline $\begin{array}{l}\text { Correlation } \\
\text { coefficient }\end{array}$ & & 0.61 & 0.58 & 0.20 \\
\hline & & & 0.84 & 0.59 \\
\hline & & & & 0.23 \\
\hline
\end{tabular}

The correlation coefficient between the rise time and zero-crossing time is 0.61 . The correlation coefficient between rise time and FWHM is 0.58 and correlation coefficient of rise time and amplitude is 0.2 . The correlation coefficient between zero-crossing time and FWHM is 0.84 which is very strong. The correlation coefficient of amplitude with zero-crossing time and FWHM are 0.59 and 0.23 respectively. From the above data, the relation of amplitude with rise time and FWHM is very poor. These relations of the parameters are also shown in figure 3 .

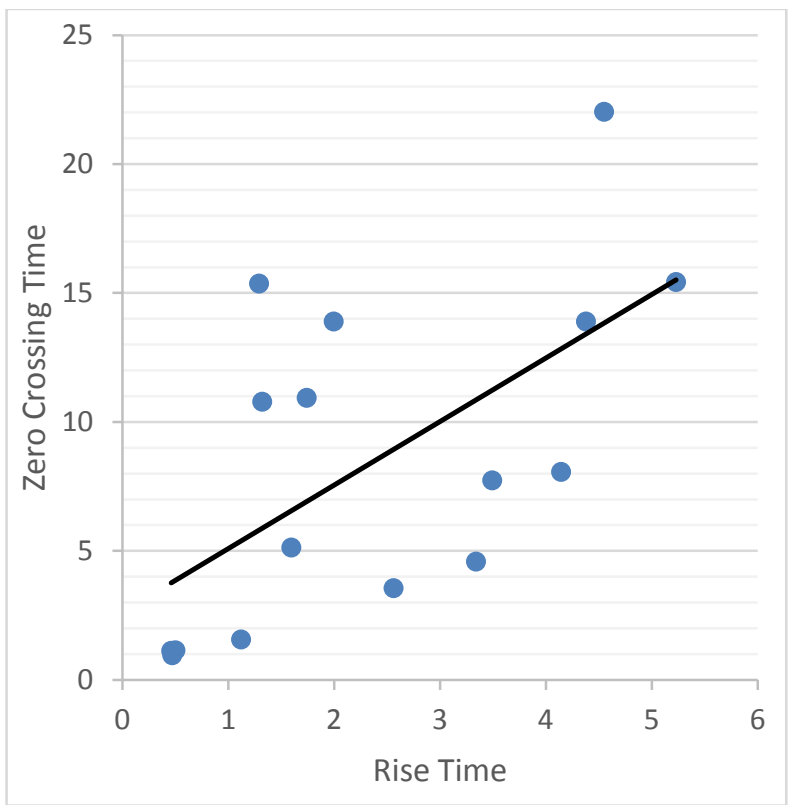

(a)

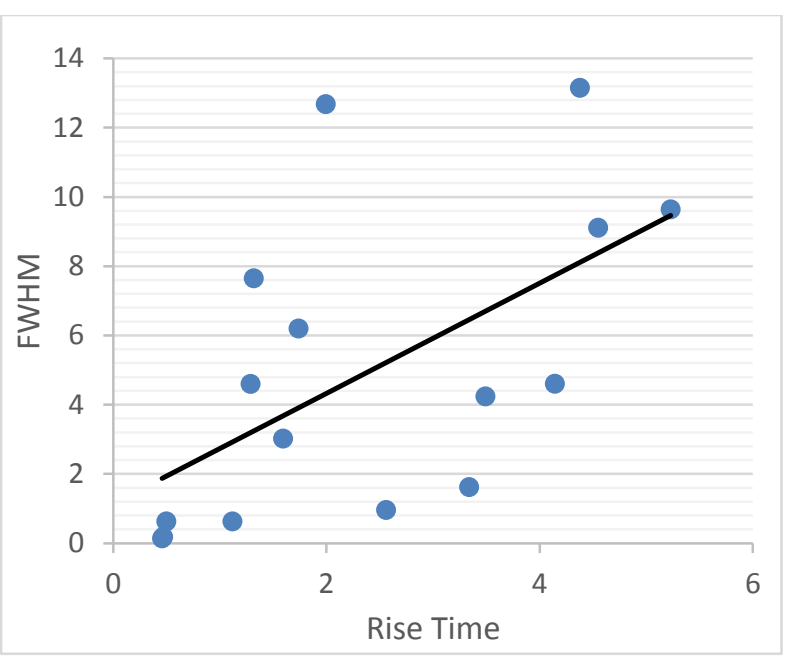

(b)

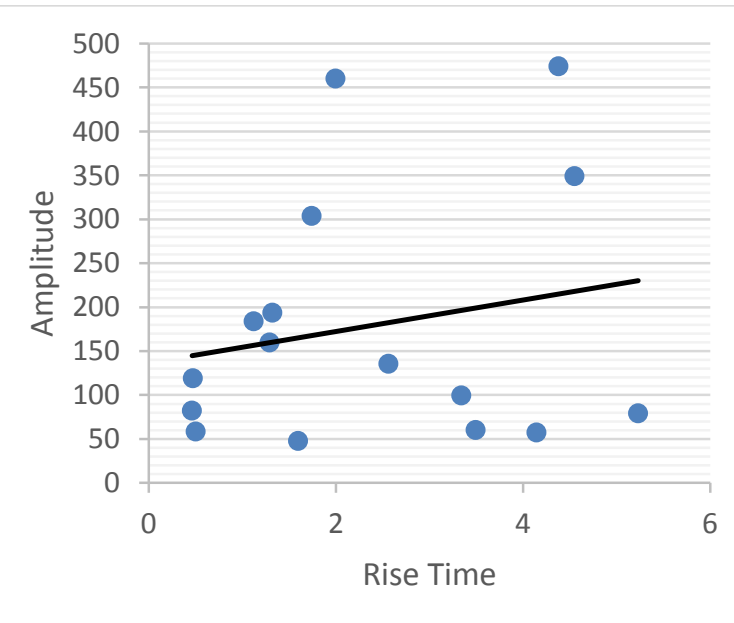

(c) 


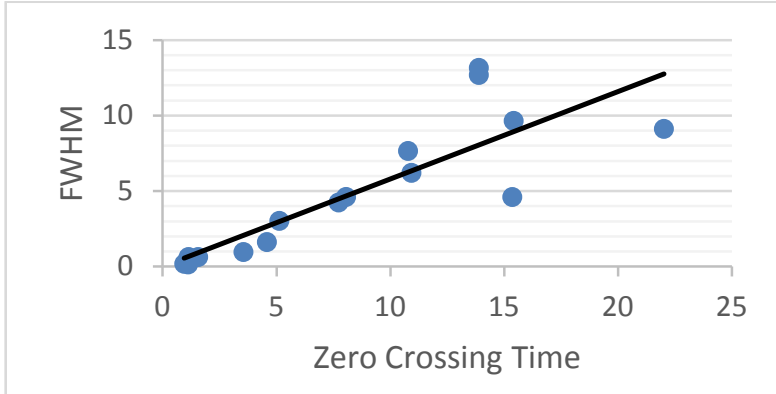

(d)

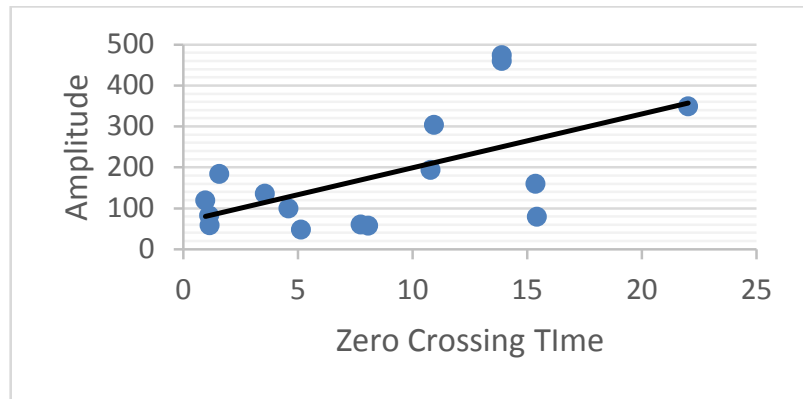

(e)

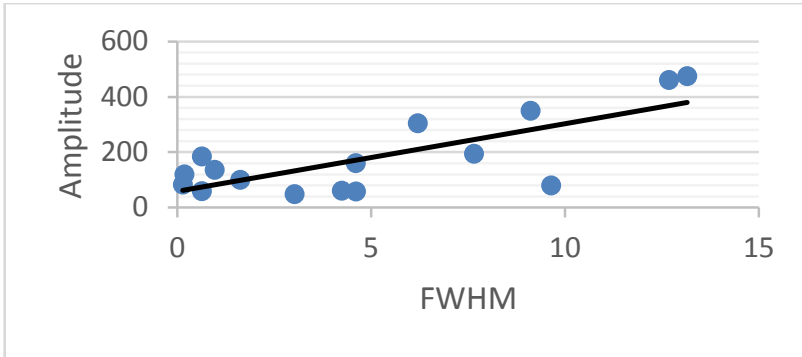

(f)

Fig. 3. Graph of the parameters: (a) Rise time vs zero-crossing time (b) Rise time vs FWHM

(c) Rise time vs Amplitude (d) Zero-crossing time vs FWHM (e) Zero-crossing time vs Amplitude (f) FWHM vs Amplitude.

\section{AFTER EARTHQUAKE (DURING EARTHQUAKE)}

We have recorded three hundred fifty-two total flashes on the $11^{\text {th }}$ and $16^{\text {th }}$ of the May 2015, after the massive earthquake. Among them one hundred fifty one flashes were taken in which one hundred seventy-two positive return strokes were recorded. The multiplicities of the strokes are mentioned in table 2. We have measured the rise time (tr), Zero crossing time $\left(\mathrm{t}_{\mathrm{z}}\right)$, field width at the half -maximum (FWHM) and amplitude of the waves which are the basic parameter of the waves. After the Earthquake, these one hundred fifty one flashes were taken in which one hundred seventy-two positive return strokes were analyzed. These are expressed also in the Table-1. For the analysis the arithmetic mean, Geometric mean, Median, Maximum value, Minimum value, Range, correlation coefficient, Standard Deviation, Variance of the parameter etc. of the parameter rise time, Zero crossing time, FWHM, amplitudes of the waves were found. The average of the rise time is $7.14 \mu \mathrm{s}$, in which G.M. is $5.42 \mu \mathrm{s}$. The average of zero-crossing time is 29.97 $\mu \mathrm{s}$ and G.M. is only $20.46 \mu \mathrm{s}$. The average of FWHM is $10.36 \mu \mathrm{s}$ but G.M. is only $7.56 \mu \mathrm{s}$. Similarly, the mean amplitude of the wave is $424.91 \mathrm{mV}$ but the G.M. is only $258.6 \mathrm{mV}$.

On these data, the rise time varies from $0.12 \mu$ s to $31.17 \mu \mathrm{s}$. So the range is $31.05 \mu \mathrm{s}$. Similarly, the zero-crossing time varies from $0.28 \mu \mathrm{s}$ to $360 \mu \mathrm{s}$ whose range is $359.72 \mu \mathrm{s}$. The FWHM varies from $0.17 \mu \mathrm{s}$ to $42.96 \mu \mathrm{s}$, so the range is $42.79 \mu \mathrm{s}$. The amplitude of the waves varies from $79.05 \mathrm{mV}$ to $3452 \mathrm{mV}$ having range $3372.95 \mathrm{mV}$. The standard deviation of the rise time is $4.57 \mu \mathrm{s}$ and the standard deviation of zero-crossing time, FWHM and amplitude are $31.48 \mu \mathrm{s}, 6.55 \mu \mathrm{s}$ and $430.5 \mathrm{mV}$ respectively. These data are summarized in the following table 5 .

Table 5: Statistics of different parameters for positive return strokes after earthquake.

\begin{tabular}{|l|r|r|r|r|}
\hline & Rise time(tr) & Zero-crossing time(tz) & FWHM & Amplitude \\
\hline Number & 179.00 & 179.00 & 179.00 & 179.00 \\
\hline AVERAGE & 7.14 & 29.97 & 10.36 & 424.91 \\
\hline G MEAN & 5.42 & 20.46 & 7.56 & 258.60 \\
\hline MEDIAN & 6.48 & 25.88 & 9.87 & 346.40 \\
\hline MAXIMUM & 31.17 & 360.00 & 42.96 & 3452.00 \\
\hline MINIMUM & 0.12 & 0.28 & 0.17 & 79.05 \\
\hline RANGE & 31.05 & 359.72 & 42.79 & 3372.95 \\
\hline
\end{tabular}




\begin{tabular}{|l|r|r|r|r|}
\hline STD & 4.57 & 31.48 & 6.55 & 430.50 \\
\hline VARIANCE & 21.00 & 996.85 & 43.17 & 186370.93 \\
\hline CORRELATION R12,R13,R14 & & 0.48 & 0.63 & 0.33 \\
\hline Correlation R23,R24 & & & 0.68 & 0.30 \\
\hline Correlation R34 & & & & 0.21 \\
\hline
\end{tabular}

Fine structures of each stroke were analyzed and different parameters were studied. Possible relation among those parameters was sought. The flashes were analyzed for duration of the stroke, rise time, FWHM, relative amplitude, etc. The correlation coefficient between rise time and zero-crossing time isfound to be .048 means that the correlation coefficient between rise time and zero-crossing time is moderate. Similarly, correlation coefficient between rise time and FWHM is found to be 0.63 which is good. Furthermore, the correlation coefficient between rise time and amplitude is found to be 0.33 which is moderate. However, the correlation coefficient between zero-crossing time and FWHM is found to be .068 which is good, but, the correlation coefficient between amplitude and zero-crossing time is found to be 0.3 which is again moderate whereas the correlation coefficient between amplitude and FWHM is found to be .021 which is poor given in figure 4 below.

These relations of the parameters are also shown in graph:

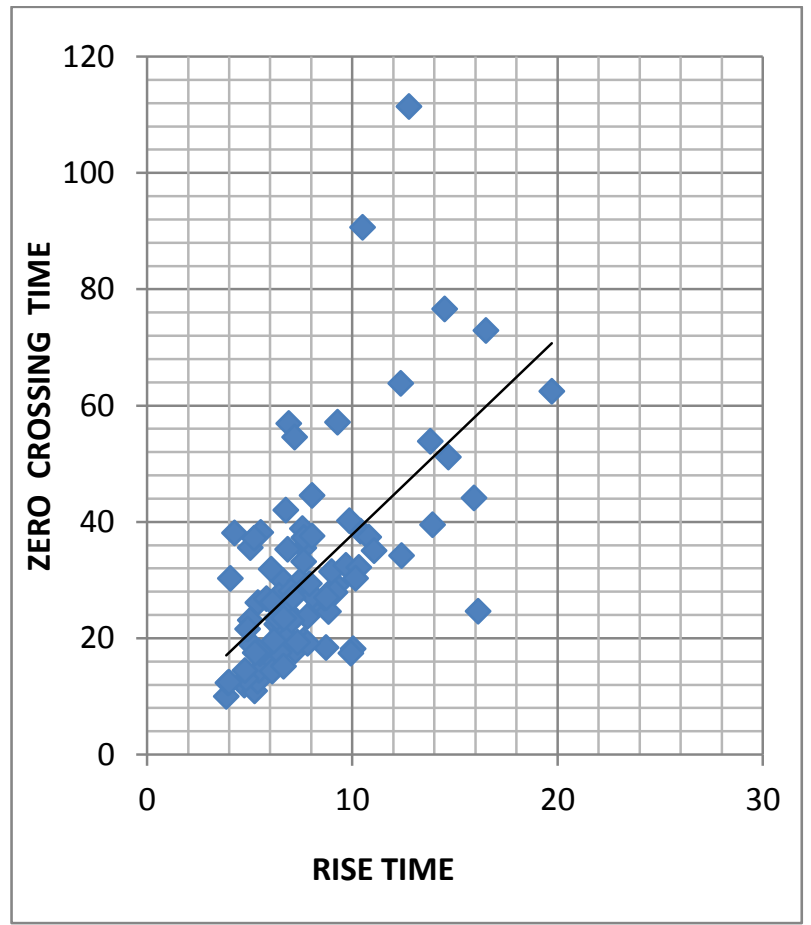

(a)

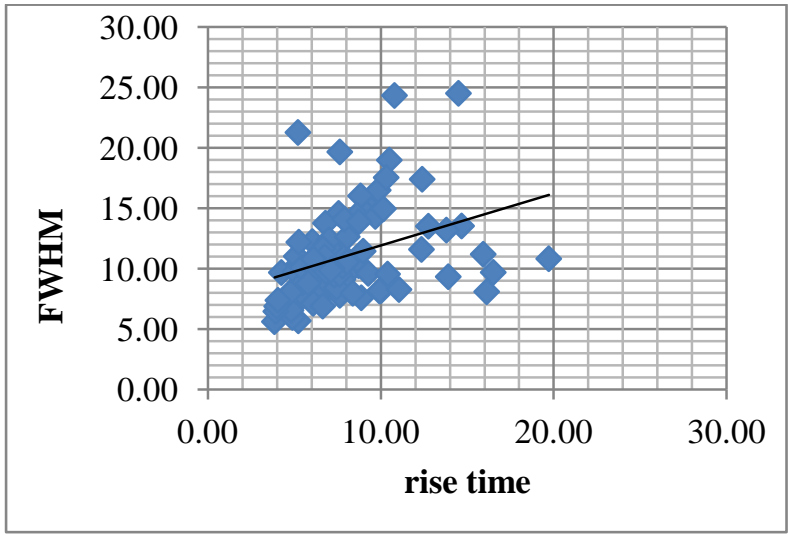

(b)

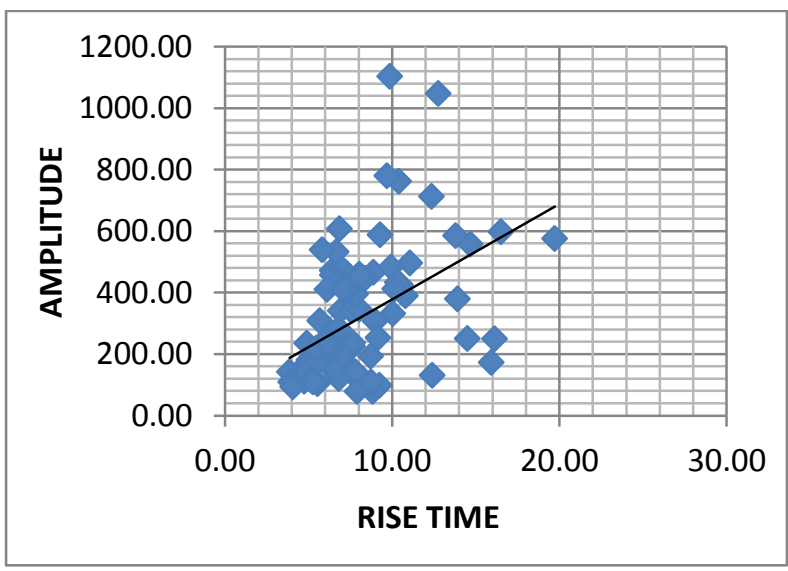

(c)

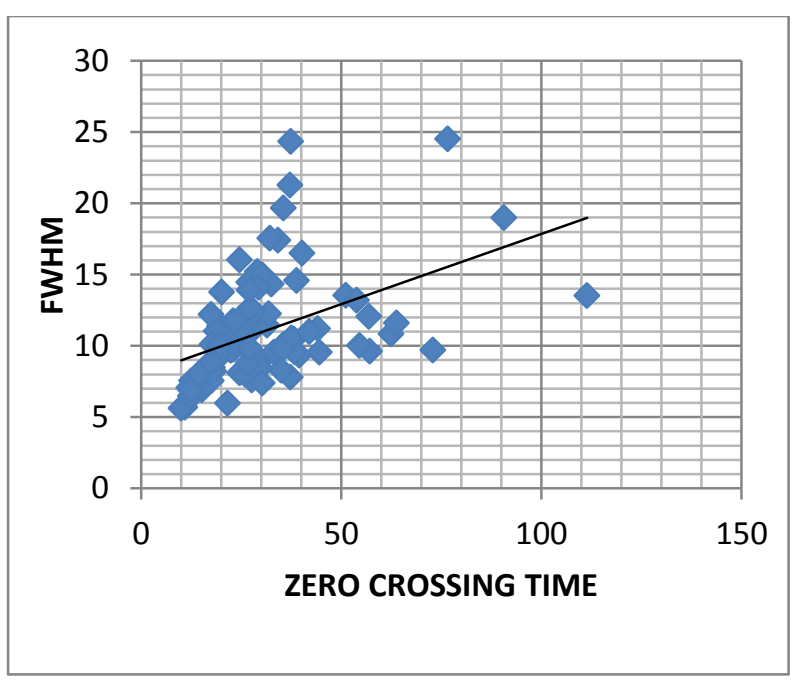

(d) 


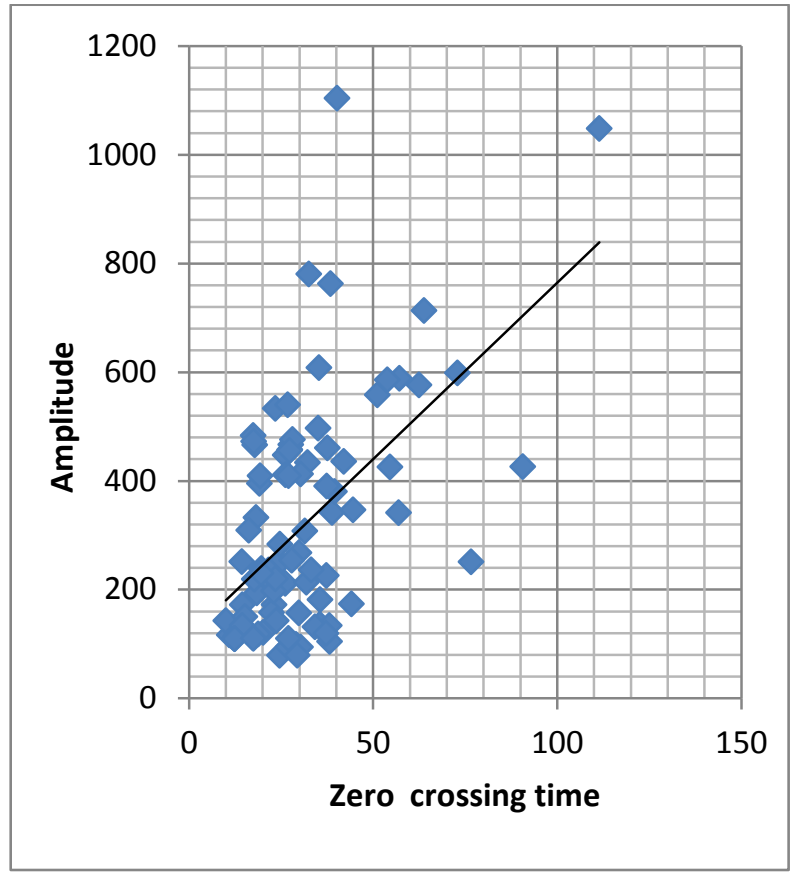

(e)

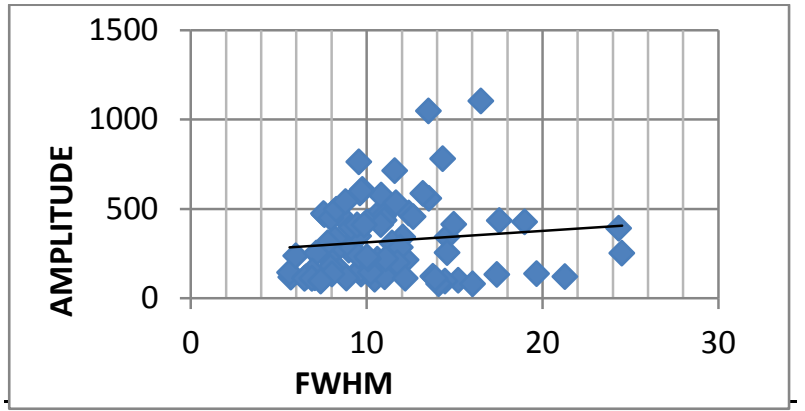

(f)

Fig. 4. Graph of the parameters: (a) Rise time vs zero-crossing time (b) Rise time vs FWHM (c) Rise time vs Amplitude (d) Zero-crossing time vs FWHM (e) Zero-crossing time vs Amplitude (f) FWHM vs Amplitude.

The examples of occurrence of lightning activity which is taken from the Google map is shown in figure 5 below.

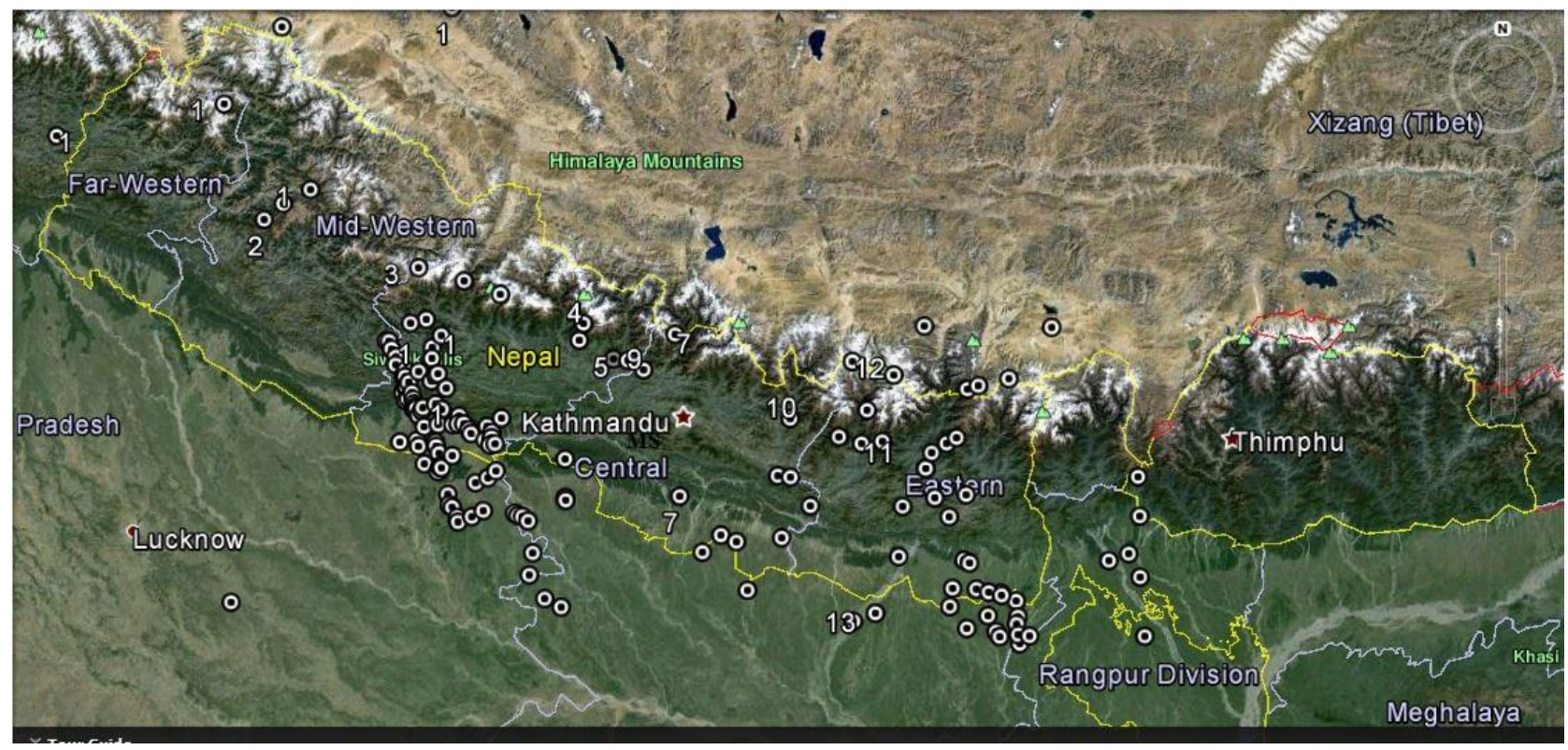

Fig. 5. Example of occurrence of lightning activity.

\section{RESULTS AND DISCUSSION}

In this present work six hundred forty-five flashes were recorded on eight thunderstorm days, in which two hundred and ninety three flashes were recorded before the earthquake and three hundred fifty-two flashes were recorded after the massive earthquake. Among them fifty seven flashes were positive and sixteen flashes were negative ground flashes before the earthquake but one hundred fifty one flashes were only positive flashes after the massive earthquake. Before the earthquake there were sixty four strokes of the fifty seven flashes having multiplicity 1.12 for positive ground flashes but for negative ground flashes, multiplicity is unity (i.e. sixteen strokes of sixteen flashes). After the massive earthquake there were one hundred seventy two strokes of the one hundred fifty one flashes having multiplicity 1.14 for positive ground flashes and there were no negative ground flashes recoded from this 
measuring station Kathmandu, Nepal. These recorded data were mentioned in the table 1 and multiplicity were mentioned in table 2 . These sixty four positive strokes before the earthquake and one hundred seventy-two positive strokes after the massive earthquake were recorded from Kathmandu, at an elevation $1300 \mathrm{~m}$ above the average sea level and these data were analyzed separately and mentioned in tables 3, 4, and 5 .
Before the earthquake, fifty flashes were single strokes flashes and seven flashes were two strokes flashes where as one hundred thirty five flashes were single strokes flashes, twelve flashes were two strokes flashes, three flashes were three strokes flashes and single flash contain four strokes flash after the massive earthquake. These data are depicted in the following table 6 and compared in percentage.

Table 6: comparison of multiplicity before and after earthquake.

\begin{tabular}{|c|c|c|c|c|}
\hline \multirow[t]{2}{*}{ Flashes contain } & \multicolumn{2}{|c|}{ Before earthquake } & \multicolumn{2}{|c|}{ After earthquake } \\
\hline & In number & In percentage & In number & In percentage \\
\hline Single strokes & 50 & 87.7 & 135 & 89.4 \\
\hline Two strokes & 7 & 12.3 & 12 & 7.9 \\
\hline Three strokes & 0 & - & 3 & 2 \\
\hline Four strokes & 0 & - & 1 & 0.7 \\
\hline Total & 57 & 100 & 151 & 100 \\
\hline
\end{tabular}

The correlation coefficient between the rise time and zero-crossing time is 0.25 and 0.48 before and after the earthquake whereas the correlation coefficient between rise time and FWHM is 0.52 and 0.63 respectively. Similarly the correlation coefficient of rise time and amplitude is 0.15 and 0.33 before and after the earthquake whereas the correlation coefficient between zero-crossing time and FWHM is 0.52 and 0.68 which is good. The correlation coefficient of amplitude with zerocrossing time and FWHM are 0.04 and 0.03 respectively before the earthquake where as the values 0.3 and 0.21 respectively after the earthquake. This relation of amplitude is very weak with zero-crossing time and FWHM before the earthquake. These data are depicted in the table -7 .

Table 7: comparison of correlation coefficient of different parameters before and after earthquake

\begin{tabular}{|l|l|l|l|l|l|l|}
\hline Correlation coefficient & $\mathrm{R} 12$ & $\mathrm{R} 13$ & $\mathrm{R} 14$ & $\mathrm{R} 23$ & $\mathrm{R} 24$ & $\mathrm{R} 34$ \\
\hline Before earthquake & 0.25 & 0.52 & 0.15 & 0.52 & 0.04 & 0.03 \\
\hline After earthquake & 0.48 & 0.63 & 0.33 & 0.68 & 0.3 & 0.21 \\
\hline
\end{tabular}

The average of the rise time is $10.15 \mu$ s before the earthquake but $7.14 \mu$ s after the earthquake.

Similarly average of zero-crossing time is $32.30 \mu \mathrm{s}$ and $29.97 \mu$ s respectively before and after the earthquake. The average of FWHM is $15.38 \mu \mathrm{s}$ and $10.36 \mu \mathrm{s}$ respectively before and after the earthquake and similarly, the mean amplitude of the wave is $567.32 \mathrm{mV}$ and $424.91 \mathrm{mV}$ respectively before and after the earthquake. In this case average of all the values of rise time, Zero crossing time, FWHM and amplitudes are higher before the earthquake than after the earthquake. Similarly the standard deviations of the parameter before the earthquake are greater than the standard deviation of the parameter after the earthquake. The standard deviation of the rise time is $8.28 \mu$ s and $4.57 \mu \mathrm{s}$ respectively before and after the earthquake the standard deviation of zero-crossing time, FWHM and amplitude are $34.13 \mu \mathrm{s}, 12.35 \mu \mathrm{s}$ and 491.76 $\mathrm{mV}$ respectively before and $31.48 \mu \mathrm{s}, 6.55 \mu \mathrm{s}$, and $430.5 \mathrm{mV}$ after the earthquake. These are depicted in the table -8 below. 
Table 8: Comparison of average and standard deviation of different parameter before and after earthquake

\begin{tabular}{|l|l|l|l|l|}
\hline Average of & Rise time & Zero crossing time & FWHM & Amplitude \\
\hline Before earthquake & $10.15 \mu \mathrm{s}$ & $32.3 \mu \mathrm{s}$ & $15.38 \mu \mathrm{s}$ & $567.32 \mathrm{mV}$ \\
\hline After earthquake & $7.14 \mu \mathrm{s}$ & $29.97 \mu \mathrm{s}$ & $10.36 \mu \mathrm{s}$ & $424.91 \mathrm{mV}$ \\
\hline S.D. of & Rise time & Zero crossing time & FWHM & Amplitude \\
\hline Before earthquake & $8.28 \mu \mathrm{s}$ & $34.13 \mu \mathrm{s}$ & $12.35 \mu \mathrm{s}$ & $491.76 \mathrm{mV}$ \\
\hline After earthquake & $4.57 \mu \mathrm{s}$ & $31.48 \mu \mathrm{s}$ & $6.55 \mu \mathrm{s}$ & $430.5 \mathrm{mV}$ \\
\hline
\end{tabular}

The examples of the signature for the positive and negative flashes are given in the following figure 6 and 7 respectively.

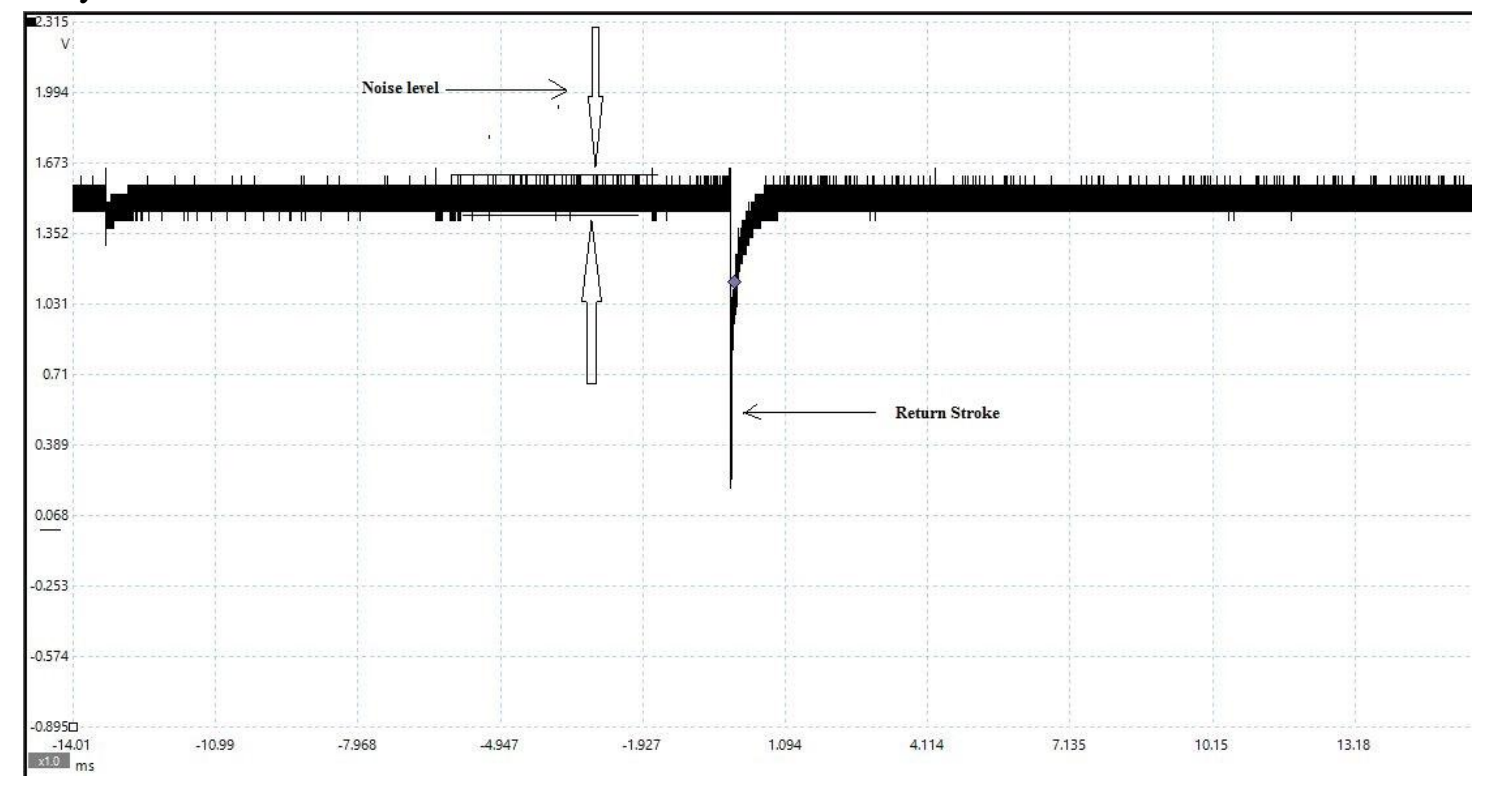

Fig. 6. Example of wave - signature for the positive flashes.

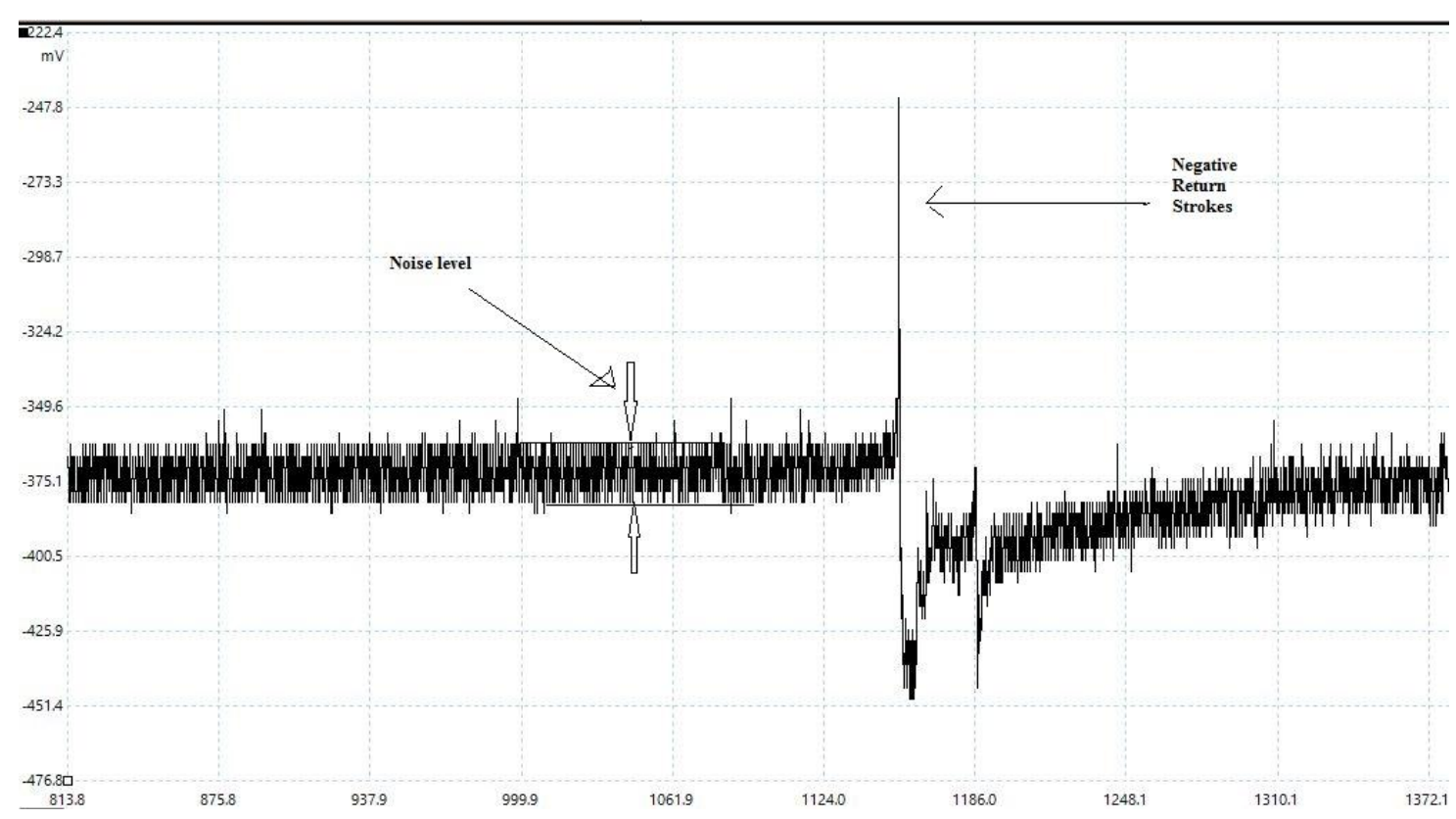

Fig.7. Wave - signature for the negative flashes. 


\section{CONCLUSION}

The characteristics of fifty seven positive flashes and sixteen negative flashes before the earthquake and one hundred fifty one positive flashes after the massive earthquake were recorded at a measuring station in Kathmandu, $\left(27^{\circ} 44^{\prime} \mathrm{N}\right.$, and $\left.85^{\circ} 19^{\prime} \mathrm{E}\right) \mathrm{Nepal}$. The numbers of strokes per flash are 1.12 and 1.14 before and after the massive earthquake. Majority of the positive ground flashes were found to be single stroke ones whereas the average number of strokes per flash is found to be 1.13 . The features of such flashes that occurred before and after the massive earthquake were separately analyzed and compared, however no significant difference could be observed.

\section{ACKNOWLEDGEMENT}

International Science Programme (ISP), Uppsala University, Sweden is acknowledged for providing the instruments necessary for this research. It would not have been possible to carry out this study without their help. We would also like to thank Central Department of Physics, Tribhuvan University for the research facility.

\section{REFERENCES}

Baral, K. N., and Mackerras, D. (1993). Positive Cloud-to-Ground Lightning Discharges in
Kathmandu Thunderstorms. Journal of Geophysical Research, 98(D6): 10331-10 340.

Barros, A. P., and Lang, T. J., (2003). Monitoring the monsoon in the Himalayas: Observation in Central Nepal, June 2001. Mon. weather review, 131: 1408-1427.

Nag, A., and Rakov, V. A. (2012). Positive lightning: An overview, new observations, and inferences. Journal of Geophysical Research, Atmospheres, 117: 2012.

Price, C., (2008). Lightning sensors for observing, tracking and now casting severe weather. Sensors, 8:157-170.

Qie, X.; Wang, Z.; Wang, D. and Liu, M. (2013). Characteristics of positive cloud-to-ground lightning in Da Hinggan Ling forest at relatively high latitude, northeastern China. Journal of Geophysical Research, Atmospheres, 118: 13393-13 404.

Rakov, V. A., and Uman, M. A. (2003). Lightning: Physics and Effects. Cambridge Univ. press, New York, 214-218.

Sharma, S. R.; Fernando, M.; Cooray, V. (2008). Narrow positive bipolar radiation from lightning observed in Sri Lanka. Journal of Atmospheric and Solar-terrestrial physics, 70: $1251-1260$.

Williams, E. R. (1989). The Tri-pole Structure of Thunderstorms. J. Geophysics. Res., 94: 13151-13167. 